\title{
Mini Review: Current tick control strategies in Pakistan are possible environmental risks
}

\author{
A. Iqbal ${ }^{*}$, M. Usman ${ }^{2}$ and M. Abubakar ${ }^{3}$ \\ ${ }^{1}$ Department of Microbiology, ${ }^{2}$ Department of Animal Sciences, Faculty of biological sciences, Quaid-i-Azam Univeristy, \\ ${ }^{3}$ National Veterinary Laboratories, NARC Gate No. 2, Park Road, Islamabad, Pakistan \\ "Corresponding Author Abdullahiqbal09@yahoo.com
}

(Received June 7, 2017; Accepted July 13, 2017)

\begin{abstract}
Ticks infestation is the major problem of cattle and buffalo of Pakistan. Tick acts as vectors of many viral, protozoal and bacterial diseases and Crimean-Congo Haemorrhagic Fever (CCHF) is one of the most lethal in that list. During the last sixteen years, many sporadic outbreaks of CCHF in Pakistan has been reported with 24 percent case fatalities. In Punjab and Sind provinces mass tick control campaigns have been started to control the tick's population and spread of zoonotic diseases through tick's. In these tick control campaigns deltamethrin and ivermectin are used extensively. We highlighted that how extensive use of deltamethrin and ivermectin can adversely affect the environment and possible alternative methods for tick control. Extensive use of deltamethrin can damage the kidneys of insect eating birds and disturb the life cycle of many aquatic organisms if deltamethrin solution is mixed with water of streams. Widespread ivermectin use in domestic animals poses some serious threats to dung beetles and other coprophagic insects as almost 60-80 percent of total dose comes in feces without any metabolism in the body of animal. Decrease in dung beetles can result in decreased dung degradation.
\end{abstract}

Keywords: Tick control, Congo fever, Deltamethrin, Insecticides, Environment Available online at http://www.vetmedmosul.org/ijvs

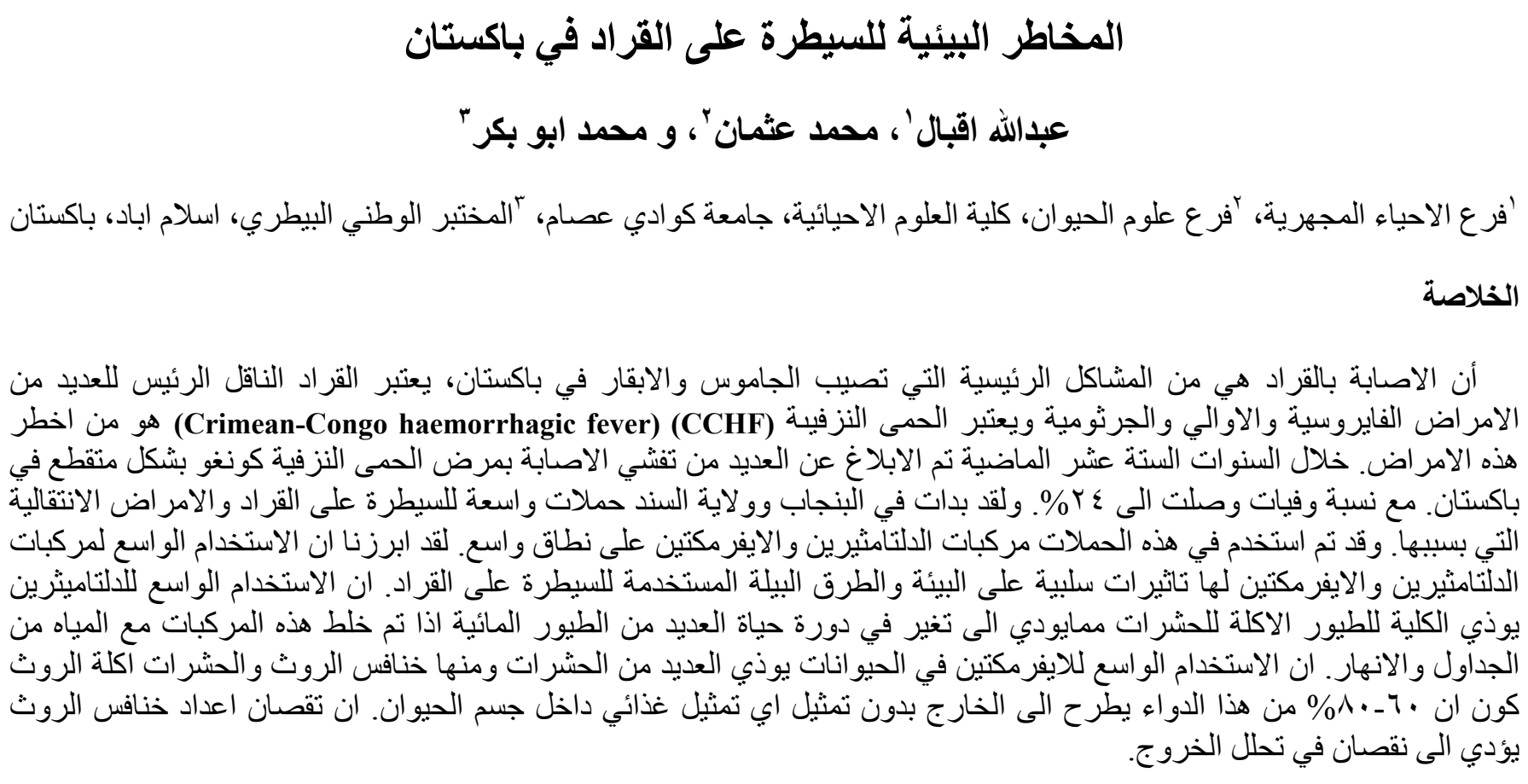




\section{Introduction}

Ticks economically are very important ectoparasites of the cattle and other domesticated animals in tropical as well as in subtropical regions. Ticks acts as vectors of many protozoans such as Theleria, Babesia, Rickettsiae such as Ehrlichia, Anaplasma, bacteria such as Listeria, Pasteurella, Staphylococcus, Brucella, Spirochaetes, and viruses such as Congo Haemorrhagic Fever Virus $(1,2)$.

Crimean-Congo Haemorrhagic Fever (CCHF) has become a serious health issue in Pakistan and many sporadic outbreaks of CCHF had been reported since 1998 (3). In 2014, from 30th March to 20th July, a total of 42 cases of Crimean-Congo Haemorrhagic Fever were reported throughout the Pakistan and 22 cases were confirmed through lab tests, among these 42 cases $24 \%$ case-fatality rate was reported (4).

To prevent outbreaks of CCHF Congo control campaigns has been started from 2012. In these campaigns Acaricides are used widely to control the population of tick so chances of direct contact between human and ticks can be decreased. Studies have suggested that the occurrence of CCHF outbreaks in Pakistan is increased significantly near Eid-UL-Adha because of an increase in chances of contact with animals having tick infestation and direct contact with the blood of animals. Due to these facts use of Acaricides is enhanced many times near Eid-ULAdha throughout the Pakistan (4).

On the other hand, use of Acaricides on large level is affecting our ecosystem too. If acaricides are used systemically their residues comes in meat, milk and can cause liver and kidney problems. Mass Spray of acaricides in dairy farms is a source of environmental pollution.

\section{Important species of ticks infesting cattle and buffaloes in Pakistan}

Figure 1 shows the infestation rate of different genera of ticks on cattle and buffalo in Peshawar, Pakistan, according to a study done by (5).

In a study performed by (6) prevalence of ticks in sheep and goat was recorded as 43.37 and $41.53 \%$ in respectively in two different livestock farms located in the Potohar region, namely Barani Livestock Production Research Institute Kherimurat, District Attock and National Agricultural Research Centre, Islamabad, Pakistan. (7) investigated the prevalence ticks in dairy cattle and buffalo in district Faisalabad, district Jhang and district Khanewal of Punjab, Pakistan. Those researchers found that tick's infestation rate in cattle was $70 \%$ and in buffaloes was $34 \%$.

\section{Impact of ticks on animals}

Tick infestation results in substantial losses to livestock farmers (8). Ticks and tick borne diseases result in loss of around US\$ 499 million per annum in India (2). In 1974 in Australia, Boophilus microplus caused a loss of 62 million USD. It is estimated that Brazil suffers around 2 billion USD per year due to tick infestation (9). Ticks causes economic losses either by directly sucking blood from host animal or indirectly by acting as vector of pathogens. Ticks causes decrease in live weight of host animal. Tick bites also lessen the quality of hides of domestic animals. Ticks infestation result in irritation and unrest in livestock that can lead to drop in their production (10). As vector of pathogens ticks transmit many pathogens that can cause diseases in human and animals such as CCHF, Lyme disease, Theileriosis, Anaplasmosis, Babesiosis and East Coast fever. B. microplus act as vector for pathogens that cause Anaplasmosis and Babesiosis (11). These losses can be curtailed if the population of ticks in the farm is kept at the lowest possible level.

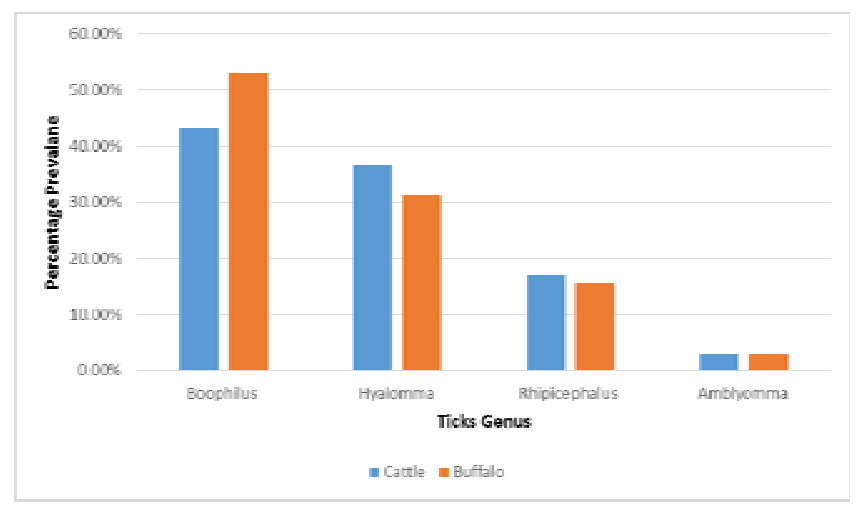

Figure 1: Prevalence of different genera of Ticks in cattle and buffalo.

\section{Impact of ticks on human health}

Tick-borne diseases in human came under the light after discovery of Lyme borreliosis. Pathogen of Lyme diseases is B. burgdorferi that is transmitted by ticks belonging to genus Ixodes. Lyme borreliosis is now becoming the most frequently reported arthropod-borne disease in Europe, North America and China (4,12,13). Ixodes ticks also transmit many viral infections in human all over the world such as European tick-borne encephalitis, Crimean-Congo haemorrhagic fever, Kyasanur forest disease and Russian spring summer encephalitis. CCHF is transmitted by different species of genus Hyalomma. Many outbreaks of $\mathrm{CCHF}$ have been reported in recent years in Asia and Africa $(4,13)$. Kyasanur forest disease is caused by flavivirus and transmitted by Haemaphysalis. Many deaths are reported annually in India due to Kyasanur forest disease (2). Ticks of genus Dermacentor act as vector of Rickettsia rickettsii, causing agent of Rocky Mountain spotted fever. Rocky 
Mountain spotted fever has been reported from many states of the United States (14).

\section{Prevalence of ticks in different Asian countries}

There are many reports that describe the prevalence of ticks in Asian Countries. In turkey thirty-two tick species that infest mammals and birds have been reported. Ticks belonging to genera Dermacentor, Rhipicephalus and Boophilus are prevalent in Anatolia. Genus Ixodes ticks are present in Northern Turkey (15). A study conducted in Diyabakir province in Turkey by Neval Kaya demonstrated that $26.2 \%$ animals had ticks' infestation and commonly prevalent ticks were $R$. bursa, $R$. turanicus, $R$. sanguineus, Hyalomma anatolicum excavatum, $H$. anatolicum anatolicum, Haemaphysalis parva, and $H$. punctate (16).

In Iran (17) reported that $57 \%$ cattle, $62 \%$ goats and $55 \%$ sheep were infested by hard ticks. Haemaphysalis, Dermacentor and Rhipicephalus ticks were prevalent in the mountainous area and Boophilus and Ixodes ticks were found in the Caspian region. An epidemiological survey performed by (18) in Uzbekistan reported that three most prevalent ticks in Uzbekistan were Hyalomma anatolicum (34.9\%), Hyalomma detritum detritum $(31.8 \%)$, and Boophilus kohlsi (30.7\%). In Iraq (19) reported presence of Hyalomma anatolicum marginatum and $H$. anatolicum anatolicum in cattle. Similarly, Rhipicephalus bursa, $R$. turanicus, Hyalomma spp. and Haemaphysalis parva were reported in sheep and goats.

Many human tick-borne diseases have reported from China such as Crimean-Congo hemorrhagic fever (called as Xinjiang hemorrhagic fever in China), Lyme disease, Forest encephalitis, Q-fever and tularemia all these indicated the prevalence of ticks in China $(20,21)$.

Commonly prevalent genera of ticks in India are Hyalomma, Rhipicephalus, Boophilus, Haemaphysalis and Argas. According to different studies performed in Bangladesh it is reported that Boophilus microplus infested $28.3 \%$ cattle and $6.3 \%$ goats. Rhipicephalus sanguineus was more prevalent in canines as compared to other ticks. In India, Pakistan and Bangladesh tick load is increased during May-June due to favorable environmental conditions in April that lead to increased embryonic development and larval activity. During AugustSeptember heavy rainfall in results in reduction in ticks as rain washes away larva (2).

\section{Current ticks control strategy in Pakistan}

Acaricides are periodically used in dairy farming to control the ticks. Ticks control by the use of acaricides can be used against the ticks free living stages that are in the environment or can be against the stages of parasite on the host. In Pakistan acaricides are applied in many different ways. Sometimes acaricides are applied by spraying on animals, by dipping of animals, by injections and by spot or pour-on are methods.

Wide range of acaricides is currently available in the market. Pyrethroids are easily degraded, safe as well as effective acaricides. EcofleeceTM is a formulation by Prix Pharmaceutica, which contains $10 \mathrm{EC}$ cypermethrin in it. The dose recommended for good acaricidal effect is $1 \mathrm{ml}$ of the drug in 1 liter of water. Sometimes farmers use the insecticides of the crops that contains cypermethrin. The product Neguvon contains trichlorofon, a chemical belonging to organophosphate group. When used as a spray or dip, then concentration of this drug which is recommended is $0.15 \%$.

Acaricidal drugs that can be applied to the animal's back are pour-on, they are costly, but much easier to use than others. These pour-on chemicals work by absorption in the blood so when tick feed on that blood these chemicals cause the death of ticks. Use of Ivermectin against ticks belonging to genus Boophilus @ $200 \mu \mathrm{g} / \mathrm{kg}$ provides very good results (8). Regardless of choice of method for the application of these acaricides, the sheds of animals must be periodically sprayed by the acaricides by preparing the solution at double strength than prepared for the spray or dip (8).

\section{Adverse effects of pyrethroids}

Use of acaricidal dugs has many drawbacks like their residues comes in meat, milk and also causes environmental pollution. Some insecticides have been made from chrysanthemumic acids in the form of semisynthetic derivatives called as 'Pyrethroids', and they are likely to be a little bit toxic to mammals and more efficient as compared to pyrethrins that are natural (22).

Allethrin is the most common synthetic pyrethroid. World Health Organization labelled Deltamethrin as a moderately hazards chemical. Interaction of pyrethroids with GABA receptors makes a complex known as ionophore complex. This ionophore complex lead to neurotoxicity (23).

\section{Human toxicity}

Pyrethroids are highly used in animal husbandry. Pyrethroids are mildly toxic to humans but still in 1982, 200 cases of acute occupational poisoning by pyrethroids were reported in China (24). Most of the cases were due to deltamethrin exposure and later on by cypermethrin, fenpropathrin, cyfluthrin, fenvalerate exposure. After these incidents an epidemiological survey was conducted in China in which it was seen that there was $0.38 \%$ prevalence of mild acute poisoning by pyrethroids in 3,113 spray men (25).

Additionally, indoor spray of pyrethroids can be the source of chronic exposure and adsorption of pyrethroids by numerous objects such as dust particles makes them 
probable indoor toxicants (26). Pyrethroid poisoning symptoms initiate with epigastric pain, dizzy feeling, headache, anorexia, nausea, fatigue, muscular fasciculation increased secretion of the stroma and vomiting. In severe situations, some additional symptoms like convulsion attacks, cyanosis, difficult breathing and edema of the pulmonary system are frequently observed (27). Because of the disturbance to cell membrane bilayer when pyrethroids interfere the order of lipid packing of mast cells and basophils which cause the release of histamine $(27,28)$.

Pyrethroids which are synthetic in nature are such acaricides that are lipophilic in nature and their chemical composition and biological activities seems to be related directly (29). Duration and severity of symptoms depend upon exposure and can range from a few minutes to more than 20 hours (30).

\section{Toxicity in aquatic organisms}

Pyrethroids can cause many disturbing effects on the life cycle of aquatic invertebrates. Just like mosquito and flies LC50 value for aquatic invertebrates is less than 1.0 parts per billion (30). Aquatic invertebrates, those are highly sensitive to pyrethroids includes nymphs of the mayfly, certain large crustaceans, surface living insects, benthic organisms and zooplankton (31).

It is also reported that even at non-lethal concentration, pyrethroids can result in a change of behavior of aquatic invertebrates. Deltamethrin, cypermethrin and permethrin all are very toxic for fish, lobster and shrimp (32). In fish, poisoning by fenvalerate causes the symptoms like disturbance in schooling behavior, surface swimming, restlessness, coughing, increased secretion of mucus from the gills and before death shaking of the head (31).

\section{Toxicity in birds}

Pyrethroids affect the birds indirectly, due to the risk of their supply of food. Most prone birds are small insect eating birds and waterfowl (32). Birds can tolerate the pyrethroids better as compared to the mammals because of fast metabolism, low absorption and rapid elimination $(33,34)$.

\section{Mammalian toxicity}

Pyrethroids are very powerful neurotoxicating agents in invertebrates and vertebrates, but in mammal's acute toxicity is less. In mammal's toxicity is less due to their rapid and speedy biotransformation and excretion from the body, usually along with the urine in the shape of metabolites that are non-active (35).

\section{Adverse effects of ivermectin:}

Avermectin group contains many macrocylic lactone chemicals such as ivermectin, doramectin, eprinomectin, moxidectin and abamectin (36). Among all members of avermectin group ivermectin is most widely used in Asia. Although it provides an effective and inexpensive way for treating and controlling ectoparasites but it also affects the biodiversity in farmland systems (37). After administration, $62 \%-98 \%$ of the ivermectin of total dose come in the feces without any metabolism in the body $(37,38)$.

Many studies supported the fact that ivermectin does not rapidly degrade in dung and remains for long periods at such concentrations that are harmful to coprophagous fauna (39-41). (42) reported the presence of $13 \mu \mathrm{g}$ of ivermectin per $\mathrm{kg}$ of cattle dung after 180 days in Argentina. Presence of ivermectin in dung effect the life cycle of dung beetles, dipteran larvae and such birds who eat these invertebrates (39).

Withdrawal period of ivermectin from cattle range from 21-55 days depending on dosage and route of administration (43). Prolong withdrawal time from meat and other edible parts of the animals also hinders the use of ivermectin in food animals. But in Pakistan use of ivermectin in animals is enhanced near Eid-UL-Adha irrespective of its side effects on human health.

\section{Alternative strategies for tick control}

Animals that are newly purchased should not keep in the same shed with the already present animals. Newly purchased animals must be treated with acaricidal drugs if ticks are present on them. Rotational grazing can decrease the population of one-host ticks such as Bophilus microplus (44).

Sahiwal cattle (Bos indicus) are much more resistant to ixodid ticks than European (Bos taurus) breeds of cattle. There are some factors that contribute to tick resistant ability of Zebu cattle such as they have very thick and mobile skin that is covered with hair that are straight, short, and non-medulated (wooly hair on the skin of European cattle), blood circulation of skin is good and high, panniculus muscles are well developed, when ticks and flies sit on the skin than hair become erected and repels the ticks are repelled by sebum secretion in hair (45).

The host's resistance can decline due to many factors such as host stress, any disease, lactation and malnutrition (46). Tick resistance traits are heritable and bulls that are selected for their resistance ability by breeding with them this ability can be enhanced in their progeny as well (45). There are many natural enemies for ticks that can be considered as a weapon of biological control for ticks. Some other predators like rodents, ants, birds and spiders play certain role in the control of ticks. Ox peckers eat the ticks from animals and studies revealed the fact that burden of the ticks is low in those buffaloes and cattle that 
are tied or stay in summers beneath the trees, because birds in the trees eat ticks (46).

Now a day, widespread use of chemicals for control of ticks resulted in drastic decrease the number of such birds that eat ticks. In cattle sheds, poultry chick raising is very helpful because they pick the ticks from the animal's body and decrease ticks from the surrounding area of the farm too. If chicken eats one single engorged female tick that can diminish several thousand larvae (47).

Biological control is the best option to control the ticks because of the resistance against acaricides and residues of insecticides in animal origin food (48). Certain herbs and plants have the ability to kill the ticks, inhibit their growth, against molting and repel the ticks. There are so many reports on the extracts of the plant's effect on the species of the ticks. (47) studied that Sitaphal (Annona squamosa) and Neem (Azadirachta indica) alcoholic extracts could be very effective against Boophilus and Hyalomma.

Many people in Punjab province feed $250 \mathrm{mg}$ of powdered Tara mira (Roquette, Eruca sativa) to cattle for control of. Tick load is reduced by this recipe and it also increases the milk yield. In Punjab, sometimes farmers apply the common salt solution on the body of animal for the control of ticks. Development of vaccine against ticks is also a useful option to reduce the ticks (47). Vaccines can be used to protect animals against ticks and tick borne diseases. Due to harmful effects of acaricides in many European countries recombinant vaccines against ticks became commercially available in the early 1990s. Second method is vaccination of animals against tick borne diseases. In Argentina, Australia and Israel attenuated vaccines against babesiosis have been used with great success $(48,49)$.

\section{Conclusion}

We should try to limit the use of pyrethroids and macrocylic lactone for control of ticks as these chemicals adversely affect the environment and kill many other useful insects. Biological control and vaccine against ticks are good options to control ticks without damaging normal fauna.

\section{Author's contribution}

$\mathrm{AI}$ and MA conceived the idea. AI and MU gathered the literature and all authors participated in write up and approved the manuscript.

\section{Acknowledgements}

We are really thankful to Dr. Usman Rasheed for his help in drafting manuscript.

\section{References}

1. Samish M, Ginsberg H, Glazer I. Biological control of ticks. Parasitol. 2004;129(7). doi:10.1017/s0031182004005219.

2. Ghosh S, Bansal GC, Gupta SC, Ray D, Khan MQ, Irshad H, Ahmed JS. Status of tick distribution in Bangladesh, India and Pakistan. Parasitol Res. 2007;101 Suppl 2:207-216. doi:10.1007/s00436-0070684-7

3. Altaf A, Luby S, Jamil A, Najam A, Aamir Z, Khan J, Fisher-Hoch S. Outbreak of Crimean-Congo haemorrhagic fever in Quetta, Pakistan: contact tracing and risk assessment. Trop Med Internat Health. 1998;3(11):878-882. doi:10.1046/j.1365-3156.1998.00318.x

4. Hussain B, Iqbal A, and Abubakar M. Crimean-Congo Hemorrhagic Fever (CCHF): An emerging disease in Pakistan. Vet Sci Res Rev. 2016;2(1):11-22.

5. Manan A, Khan Z, Ahmed B. Prevalence and identification of ixodid tick genera in frontier region Peshawar. J Agri Biol Sci. 2007;2(1):21-25.

6. Irshad N, Qayyum M, Hussain M, Khan MQ. Prevalence of tick infestation and theileriosis in sheep and goats. Pak Vet J. 2010;30(3):178-180.

7. Ali Z, Maqbool A, Muhammad K, Khan MS, Younis M. Prevalence of theileria annulata infected hard ticks of cattle and buffalo in Punjab, Pakistan. J Anim Plant Sci. 2013;23(1):20-26.

8. Radostits OM, Done SH. Veterinary medicine: a textbook of the diseases of cattle, sheep, pigs, goats, and horses. Edinburg: Saunders Elsevier; 2007.

9. Rajput ZI, Hu S, Chen W, Arijo AG, Xiao C. Importance of ticks and their chemical and immunological control in livestock. J Zhejiang Univ Science B. 2006;7:912-921.

10. Douglas D, Colwell Filipe Dantas-Torres, Domenico Otranto. Vector-borne parasitic zoonoses: Emerging scenarios and new perspectives. Vet Parasitol. 2011;182:14-21.

11. Peter RJ, van den Bossche P, Penzhorn BL, Sharp B. Tick, fly, and mosquito control lessons from the past, solutions for the future. Vet Parasitol. 2005;132:205-215.

12. Wu GH, Jiang ZK: Lyme disease and prevention and control of ticks. Chinese J Hyg Insect. 2007;5:312-314.

13. Leblebicioglu H, Ozaras R, Irmak H, Sencan I. Crimean-Congo hemorrhagic fever in Turkey: Current status and future challenges. Antiviral Res. 2016;126:21-34.

14. Estrada-Peña A, Ayllón N, de la Fuente J. Impact of climate trends on tick-borne pathogen transmission. Front Physiol. 2012;3:64-10.

15. Aydin L, Bakirci S. Geographical distribution of ticks in Turkey. Parasitol Res. 2007;101 Suppl 2:163-166.

16. Jabbar A, Hatice Alp, Muhammed A, Ulrike S. Current status of ticks in Asia. Parasitol Res. 2007;101Suppl 2:159-162.

17. Bursali A, Keskin A, Tekin S. A review of the ticks (Acari:Ixodida) of Turkey: species diversity, hosts and geographical distribution. Exp Appl Acarol. 2012;57:91-104.

18. Rahbari S, Nabian S, Shayan P. Primary report on distribution of tick Fauna in Iran. Parasitol Res. 2007;101,175-177.

19. Rasulov I. Ticks status in central Asia with a special emphasis on Uzbekistan. Parasitol Res. 2007;101 Suppl 2:183-186. doi:10.1007/s00436-007-0691-8

20. Omer LT, Kadir MA, Seitzer U, Ahmed JS. A survey of ticks (Acari:Ixodidae) on cattle, sheep and goats in the Dohuk Governorate, Iraq. Parasitol Res. 2007;101 Suppl 2:179-181. doi:10.1007/s00436-007-0690-9

21. Zhang SH. The latest research progress of tick and the tick-borne diseases. Anhui J Prev Med. 2012;18:45-48.

22. Veiga LP, Souza AP, Bellato V, Sartor AA, Nunes AP, Cardoso HM. Resistance to cypermethrin and amitraz in Rhipicephalus (Boophilus) microplus on the Santa Catarina Plateau, Brazil. Rev Bras Parasitol Vet. 2012;21:133-136. 
23. Casida JE, Gammon DW, Glickman AH, Lawrence LJ. Mechanisms of selective action of pyrethroid insecticides. Annual Rev Pharmacol Toxicol. 1983;23:413-438.

24. He F, Wang S, Liu L. Clinical manifestations and diagnosis of acute pyrethroid poisoning. Arch Toxicol.1989;63:54-58.

25. Chen SY, Zhang ZW, He FS, Yao PP, Wu YQ, Sun J X, Li QG. An epidemiological study on occupational acute pyrethroid poisoning in cotton farmers. Occupat Environ Med. 1991;48(2):77-81. doi:10.1136/oem.48.2.77

26. Soderlund DM, Clark JM, Sheets LP, Mullin LS, Piccirillo VJ, Sargent D. Mechanisms of pyrethroid neurotoxicity: implications for cumulative risk assessment. Toxicol. 2002;171:53-59.

27. Michelangeli F, Robson MJ, East JM, Lee AG. The conformation of pyrethroids bound to lipid bilayers. Biochimica et Biophysica Acta 1990;1028:49-57.

28. Carlson JE, Villaveces JW. Hypersensitivity pneumonitis due to pyrethrum. Report of a case. J Amer Med Assoc. 1977;237:17181719.

29. Gentz MC, Murdoch G, King GF. Tandem use of selective insecticides and natural enemies for effective, reduced-risk pest management. Biol Control. 2010;52:208-215

30. Sayeed S, Parvez S, Pandey B, Hafeez R, Haque S. Rai suddin. Oxidative stress biomarkers of exposure to deltamethrin in freshwater fish, Channa punctatus Bloch. Ecotoxicol Environm Safety. 2003;56:295-301.

31. Tilak KS, Veeraiah K, Vardhan KS. Toxicity and residue studies of fenvalerate to the freshwater fish Channa punctatus (Bloch). Bull Environ Contamin Toxicol. 2003;71:1207-1212.

32. Tandon SS, Srivastava PP, Mukherjee SC, Saharan N. Acute toxicity of synthetic pyrethroids to Indian major carp, Catla catla L. Bull Environ Contamin Toxicol. 2005;74:610-613.

33. Boatman ND, Brickle NW, Hart JD, Milsom TP, Morris AJ, Murray AW, Robertson PA. Evidence for the indirect effects of pesticides on farmland birds. Ibis 2004;146:131-143. doi:10.1111/j.1474919x.2004.00347.x

34. Mueller-Beilschmidt D. Toxicology and environmental fate of synthetic pyrethroids. J Pesticide Reform 1990;10(3):32.

35. Kranthi KR, Jadhav D, Wanjari R, Kranthi S, Russell D. Pyrethroid resistance and mechanisms of resistance in field strains of Helicoverpa armigera (Lepidoptera: Noctuidae). J Econo Entomol. 2001;94:253-263.

36. Campbell WC, Benz GW. 'Ivermectin: A review of efficacy and safety', J Vet Pharmacol Therapeu. 1984; 7:1-16. http://dx.doi. $\operatorname{org} / 10.1111 / \mathrm{j} .1365-2885.1984 . t b 00872 . x$
37. Floate KD, Wardhaugh KG, Boxall ABA, Sherratt N. Faecal residues of veterinary parasiticides: non-target effects in the pasture environment. Annual Rev Entomol. 2005;50:153-179.

38. Kryger U, Deschodt C, Scholtz CH. Effects of fluazuron and ivermectin treatment of cattle on the structure of dung beetle communities. Agricul Ecosyst Enviro.2005;105(4):649- 656.

39. O'Hea NM, Kirwan L, Giller PS, Finn JA. Lethal and sub-lethal effects of ivermectin on north temperate dung beetles, Aphodius ater and Aphodius rufipes (Coleoptera: Scarabaeidae). Insect Conservation Diversity 2010;3:24-33.

40. Hempel H, Scheffczyk A, Schallnaß HJ, Lumaret JP, Alvinerie M, Römbke J. Toxicity of four veterinary parasiticides on larvae of the dung beetle Aphodius constans in the laboratory. Environ Toxicol Chem. 2006;25(12): 3155-3163. DOI: 10.1897/06-022R2.

41. Hutton SA, Giller PS. Intra- and interspecific aggregation of north temperate dung beetles on standardised and natural dung pads: the influence of spatial scale. Ecological Entomol. 2004;12:594- 605.

42. Suarez VH, Lifschitz AL, Sallovitz JM, Lanusse CE. Effects of ivermectin and doramectin faecal residues on the invertebrate colonization of cattle dung. J Appl Entomol. 2003;127:481-488.

43. Toutain PL, Upson DW, Terhune TN, McKenzie ME. Comparative pharmacokinetic of doramectin and ivermectin in cattle. Vet Parasitol. 1997;72:3-8.

44. Mondal D, Sarma K, Saravanan M. Upcoming of the integrated tick control program of ruminants with special emphasis on livestock farming system in India. Ticks Tick-borne Diseases. 2013;4(1-2): 110. doi:10.1016/j.ttbdis.2012.05.006.

45. Graf JF, Gogolewski R, Leach-Bing N, Sabatini GA, Molento MB, Bordin EL, et al. Tick control: an industry point of view. Parasitol. 2004;129,S427-S442 10.1017/S0031182004006079

46. Willadsen P. Anti-tick vaccines. Parasitol. 2004;129(7). doi: 10. 1017/s0031182003004657.

47. Ghosh S, Azhahianambi P, Fuente JD. Control of ticks of ruminants, with special emphasis on livestock farming systems in India: present and future possibilities for integrated control-a review. Exp Appl Acarol. 2006;40(1):49-66. doi:10.1007/s10493-006-9022-5.

48. Parizi LF, Githaka NW, Logullo C, Konnai S, Masuda A, Ohashi K, et al. The quest for a universal vaccine against ticks: Cross-immunity insights. Vet J. 2012;194:158-165.

49. Guerrero FD, Miller RJ, Pérez de León AA. Cattle tick vaccines: Many candidate antigens, but will a commercially viable product emerge? Int J Parasitol. 2012;42:421-427. 